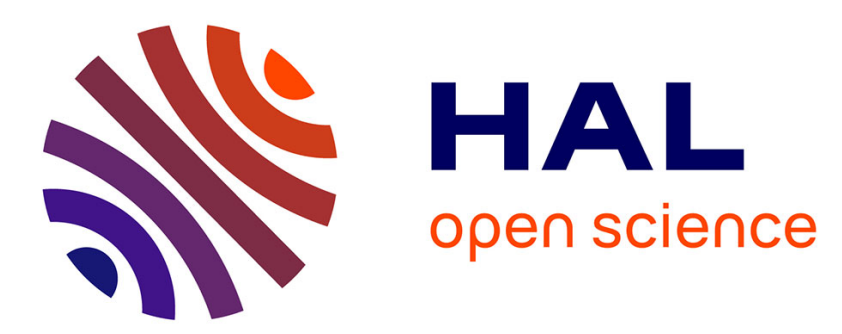

\title{
TARANIS - Scientific payload and mission strategy
}

Jean-Louis Pinçon, E. Blanc, P.L. Blelly, Michel Parrot, Jean-Louis Rauch, J.A. Savaud, Elena Seran

\section{To cite this version:}

Jean-Louis Pinçon, E. Blanc, P.L. Blelly, Michel Parrot, Jean-Louis Rauch, et al.. TARANIS - Scientific payload and mission strategy. 2011 XXXth URSI General Assembly and Scientific Symposium, Apr 2011, Istambul, Turkey. insu-01555806

\section{HAL Id: insu-01555806 https://hal-insu.archives-ouvertes.fr/insu-01555806}

Submitted on 8 Jul 2020

HAL is a multi-disciplinary open access archive for the deposit and dissemination of scientific research documents, whether they are published or not. The documents may come from teaching and research institutions in France or abroad, or from public or private research centers.
L'archive ouverte pluridisciplinaire HAL, est destinée au dépôt et à la diffusion de documents scientifiques de niveau recherche, publiés ou non, émanant des établissements d'enseignement et de recherche français ou étrangers, des laboratoires publics ou privés. 


\title{
TARANIS - scientific payload and mission strategy
}

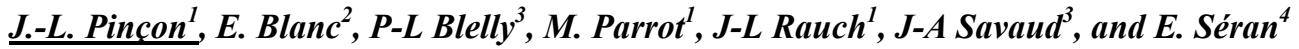 \\ ${ }^{1}$ LPC2E, University of Orléans - CNRS, 3A av. Recherche Scientifique, 45071 Orléans, France. \\ jlpincon@cnrs-orleans.fr, mparrot@cnrs-orleans.fr, Jean-Louis.rauch@cnrs-orleans.fr \\ ${ }^{2}$ DASE/LDG, CEA Bruyères-le-Châtel, 91297 Arpajon, France. Elisabeth.Blanc@cea.fr \\ ${ }^{3}$ URAP, University of Toulouse - CNRS, 9 av. Colonel Roche, 31028 Toulouse, France. \\ Pierre-Louis.Blelly@cesr.fr, Jean-Andre.Sauvaud@cesr.fr \\ ${ }^{4}$ LATMOS, IPSL - CNRS, 4 place Jussieu, 75005 Paris, France. Elena.Seran@latmos.ipsl.fr
}

\begin{abstract}
On December 2010 the implementation phase of the TARANIS micro-satellite was authorized by the French space agency. TARANIS is dedicated to the study of impulsive transfers of energy between the Earth atmosphere and the space environment, and more precisely to the physics of the Transient Luminous Events (TLEs) and of the Terrestrial Gamma ray Flashes (TGFs). By 2015 TARANIS will provide combined Nadir observations of TLEs and TGFs, high resolution measurements of energetic electrons, and wave field measurements. The strategy adopted to maximize the scientific return of the data is presented.
\end{abstract}

\section{Introduction}

In Celtic mythology Taranis was the god of thunder. The mission TARANIS (Tool for the Analysis of RAdiation from lightNIng and Sprites) is funded and operated by the French space agency CNES. This is a low altitude satellite to be launched by 2015 and dedicated to the study of impulsive transfers of energy between the Earth atmosphere and the space environment. Such impulsive transfers, pointed out by the observation at ground and on satellite (FORMOSAT 2) [1] of Transient Luminous Events (TLEs) and the detection on satellites (BATSE, RHESSI, Fermi-GBM, Agile) [2 - 5] of Terrestrial Gamma ray Flashes (TGFs), are observed above active stormy areas and appear to be correlated to lightning activity. To answer the numerous remaining questions about the physics of TLEs and TGFs, the TARANIS mission will provide a set of unprecedented and complementary measurements [6]. Specific examples include:

- $\quad$ Combined images of TLEs and TGFs (through fast micro-cameras and photometers, nadir-viewing and X-ray and Gamma-ray measurements) and the associated measurements of relativistic electrons and wave fields;

- High resolution measurement of energetic electrons in energy, pitch angle and time allowing to detect runaway electrons as well as Lightning-induced Electron Precipitation and to track natural and man-made controlled variability of the radiation belts;

- Onboard wave field measurements in a frequency range running from DC to $30 \mathrm{MHz}$ allowing to record radio signatures of optical and particle transient phenomena and to detect the presence of quasi-electrostatic thundercloud fields. .

\section{TARANIS mission profile}

TARANIS belongs to the CNES Myriade microsatellite family. It is a three axis stabilized satellite. The dimension of the platform is about $1 \mathrm{~m}^{3}$. The total weight is around $150 \mathrm{~kg}$, including about $35 \mathrm{~kg}$ for the scientific payload. The microsatellite subsystems include a mass memory of 16-Gbits capacity, a high rate X band telemetry (16.8 Mbits/s) for the transmission of the scientific data. TARANIS will be a two-year mission with a four-year mission as an objective. It will fly in a polar Sun-Synchronous Orbit (SSO) with an inclination of $98^{\circ}$ and an altitude close to $700 \mathrm{~km}$. TARANIS is will be launched in 2015 from Kourou as a piggy-back on a Soyouz rocket. Practically, this means a SSO orbit with a local time in the range [22H30 - 02H00] and no local time drift during the mission. Due to limitations in the power budget, in particular for the night time orbits, the scientific experiments will be switched off at high geographical latitudes (below $-60^{\circ}$ and above $60^{\circ}$ ) during the nominal operation modes. 
However, this limitation will have almost no impact regarding the coverage of regions where lightning activity is strong and therefore where the probability of observations of TLEs or/and TGFs is high. To allow the comparison with ground based measurements the absolute time accuracy onboard will be less than $1 \mathrm{~ms}$. The spacecraft pointing accuracy is such that TLEs and lightning will be localized with an error equal or less than $5 \mathrm{~km}$. Due to the available mass memory and X band telemetry, 4 GByte of data will be downloaded per day. The emphasis is put on synchronized observations of TLEs and TGF (Event Mode). Data will be transmitted to the ground at least twice per day. The TARANIS mission Centre will be developed and operated by the Laboratoire de Physique et Chimie de l'Espace et de l'Environnement (LPC2E).

\section{TARANIS scientific objectives}

TARANIS aims at providing a sufficiently complete package of novel instrumentation to answer specific questions raised by the many ground-based campaigns to observe TLEs, and by the highly successful FORMOSAT 2 and RHESSI missions. The science objectives of the TARANIS mission are into three broad categories:

- Advance physical understanding of the links between TLEs and TGFs, in their source regions, and the environmental conditions (lightning activity, variations in the thermal plasma, occurrence of extensive atmospheric showers, etc);

- Identify the generation mechanisms for TLEs and TGFs and, in particular, the particle and wave field events which are involved in the generation processes or which are produced by the generation processes;

- Evaluate the potential effects of TLEs, TGFs, and bursts of precipitated and accelerated electrons (in particular lightning induced electron precipitation and runaway electron beams) on the Earth atmosphere or on the radiation belts.

To achieve these scientific objectives, the questions to be addressed are:

1. TLEs and TGFs observations

2. Environmental conditions

3. Energy transfer between the radiation belts and the Atmosphere

4. Generation mechanisms for TLEs, TGFs, and runaway electron beams

5. Effect on the Atmosphere and on the global electric circuit

\section{TARANIS scientific payload and accommodation}

The instruments of the scientific payload required to achieve the scientific objectives of the TARANIS are described in Table 1 and their accommodation onboard the spacecraft is given by Figure 1.

Table 1: scientific payload of TARANIS

\begin{tabular}{|c|c|c|}
\hline & Instrument & PI, organizations \\
\hline MCP: & $\begin{array}{l}\text { lightning micro-camera } \\
\text { TLE micro-camera } \\
4 \text { Photometers }\end{array}$ & PI: E. Blanc, CEA/LDG (F) + Hokkaido Univ. ( J) \\
\hline XGRE: & $\begin{array}{l}3 \mathrm{X} \text { and } \gamma \text { detectors } \\
\text { - Photons : [20keV }-10 \mathrm{MeV}] \\
\text { - Relativistic e-: }[1 \mathrm{MeV}-10 \mathrm{MeV}]\end{array}$ & PI: P-L. Blelly, IRAP (F) + APC (F) \\
\hline IDEE: & $2 \mathrm{e}^{-}$detectors: $[70 \mathrm{keV}-4 \mathrm{MeV}]$ & PI: J-A. Sauvaud, IRAP (F) + Prague Univ. (Cz) \\
\hline IMM: & $\begin{array}{l}\text { triaxial search coil : }[5 \mathrm{~Hz}-20 \mathrm{kHz}] \\
\text { search coil } \mathrm{MF}:[10 \mathrm{kHz}-1 \mathrm{MHz}] \\
\text { zero plus whistler detector }\end{array}$ & PI: J-L. Pinçon, LPC2E (F) + Stanford Univ. (USA) \\
\hline IME-BF: & $\begin{array}{l}\mathrm{LF}-\mathrm{E} \text { antenna : [DC }-1 \mathrm{MHz}] \\
\text { Ion probe }\end{array}$ & PI: E. Seran, LATMOS (F) + GSFC (USA) \\
\hline IME-HF: & HF-E antenna: [100kHz $-35 \mathrm{MHz}]$ & PI: J-L. Rauch, LPC2E (F) + Prague Univ., IAP (Cz) \\
\hline MEXIC: & Power/Management of the payload & PI: M. Parrot, LPC2E (F) + SRC (PI) \\
\hline
\end{tabular}




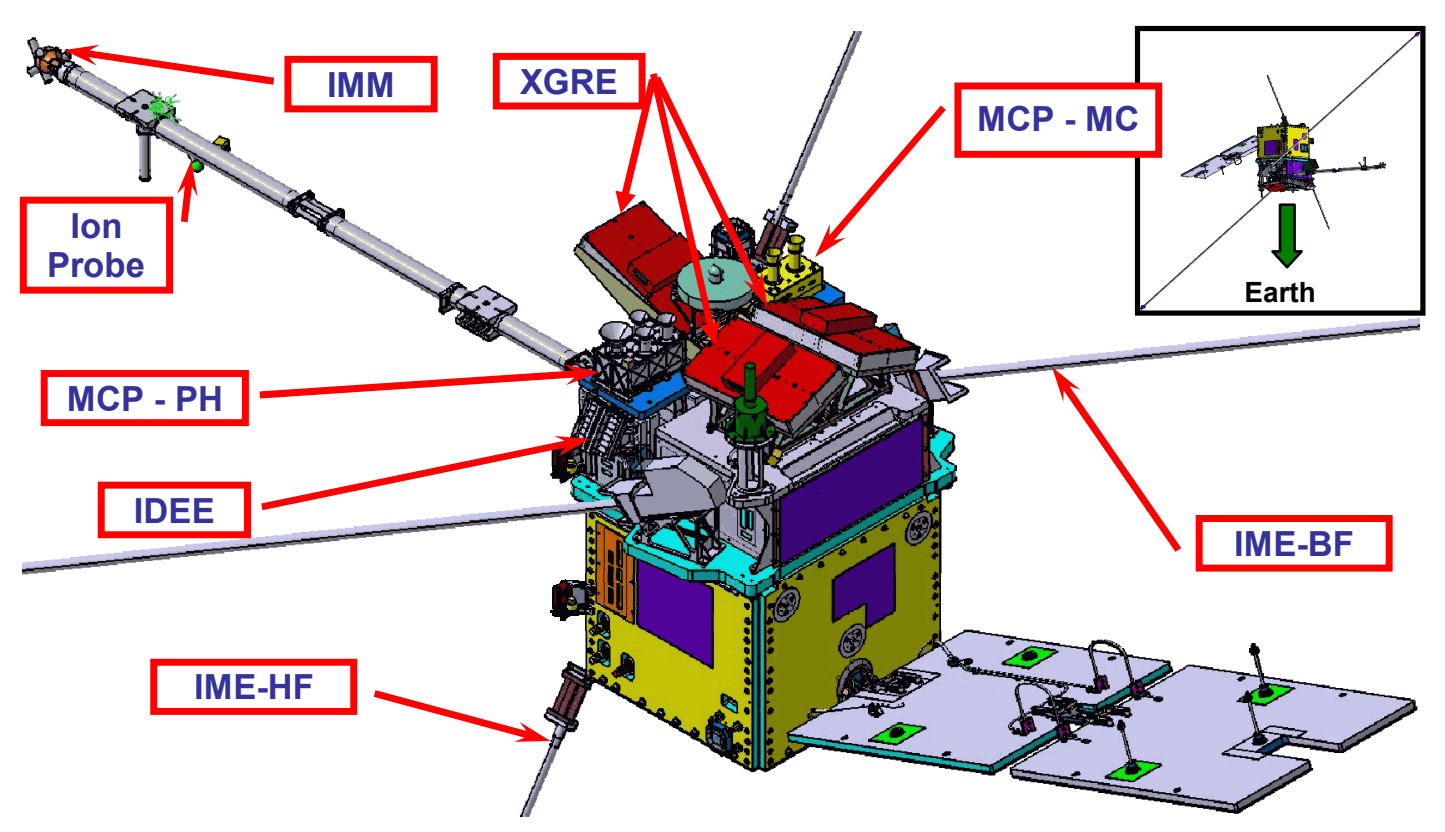

Figure 1. Scientific payload accommodation onboard TARANIS

\section{TARANIS strategy}

To maximize the scientific return of the data collected by TARANIS, the scientific payload is operated as a single instrument. The strategy adopted is twofold: a continuous monitoring of low resolution optical, field and particle data is performed and transmitted (the survey mode). Under alert, all TARANIS instrument analyzers will initiate a synchronized high resolution data mode (the event mode). Each analyzer includes memory to store high resolution data for a time interval including the event detection time.

The Event data are on-board recorded on triggering alerts only. The alert signals will be generated by the photometers (MCP-PH), the gamma detectors (XGRE), the electron detectors (IDEE), or the HF wave sensor (IMEHF). All the event management is made by MEXIC. To identify an electromagnetic signature associated with TGFs and TLEs, the parent lightning, a possible relationship between TGFs and TLEs, or an associated relativistic runaway electron beam, it is mandatory to collect simultaneously high resolution data from all TARANIS instruments. The relative time accuracy between TARANIS instruments will be less than $10 \mathrm{~ns}$, allowing meaningful intercomparison of the data sets. To allow the comparison with ground based and balloon measurements the absolute time accuracy onboard will be less than $1 \mathrm{~ms}$. The available onboard mass memory and telemetry available are such that up to about $2 \mathrm{~GB}$ of high-resolution data (event mode) will be downloaded per day.

\section{Conclusion}

The physics of thunderstorm effects on atmosphere-ionosphere coupling is a research domain that involves a large, multidisciplinary, and very active scientific community from many countries. By 2005, the scientific payload of TARANIS and the data measurement strategy adopted for the project will provide the scientific community with all the necessary inputs to solve the remaining issues about the physics of TLEs and TGFs.

\section{References}

1. A.. B. Chen, C. L. Kuo, Y. J. Lee, H. T. Su, R. R. Hsu, J. L. Chem, H. U. Frey, S. B. Mende, Y. Takahashi, H. Fukunishi, Y. S. Chang, T. Y. Liu, and L. C. Lee, Global distributions and occurrence rates of transient luminous events, J. Geophys. Res., Vol. 113, A08306, doi: 10.1029/2008JA013101, 2008. 
2. G. J. Fishman, P. N. Bhat, R. Mallozzi, J. M. Horack, T. Koshut, C. Kouveliotou, G. N. Pendleton, C. A. Meegan, R. B. Wilson, W. S. Paciesas, S. J. Goodman, and H. J. Christian, Discovery of intense gamma-ray flashes of atmospheric origin, Science, Vol. 264, 1313-1316, doi: 10.1126/science.264.5163.1313, 1994.

3. D. M. Smith, L. I. Lopez, R. P. Lin, and C. P. Barrington-Leigh, Terrestrial Gamma-Ray Flashes Observed up to $20 \mathrm{MeV}$, Science, Vol. 307, 1085-1088, 2005.

4. M. S. Briggs, G. J. Fishman, and Fermi-GBM Team, First results on terrestrial gamma ray flashes from the Fermi Gamma-ray Burst Monitor, J. Geophys. Res., Vol. 115, A07323, doi: 10.1029/2009JA015242, 2010.

8. M. Marisaldi, and AGILE Team, Detection of terrestrial gamma ray flashes up to $40 \mathrm{MeV}$ by the AGILE satellite, J. Geophys. Res., Vol. 115, A00E13, doi: 10.1029/2009JA014502, 2010.

6. F. Lefeuvre, E. Blanc, J-L Pinçon, R. Roussel-Dupré, D. Lawrence, J-A Sauvaud, J-L Rauch, H. de Feraudy, and D. Lagoutte, TARANIS - A Satellite Project Dedicated to the Physics of TLEs and TGFs, Space Sci. Rev., Vol. 137, 301-315, doi; 10.1007/s11214-008-9414-4, 2008. 